\title{
A Systematic Analysis of User Experience Dimensions for Interactive Digital Narratives *
}

\author{
Ashwathy T Revi ${ }^{10000-0002-9936-8141]}$, David E. Millard ${ }^{20000-0002-7512-2710]}$, \\ and Stuart E. Middleton ${ }^{3}[0000-0001-8305-8176]$ \\ University of Southampton
}

\begin{abstract}
Providing intelligent feedback to aid authoring has been proposed as a way to speed up authoring, give the author more control, and to enable the authoring of more complex interactive narratives. However, there is little research investigating what concrete feedback items would be useful for interactive digital narrative (IDN) creators. In this paper, we discuss potentially useful feedback items in relation to authoring goals and concerns. We perform a systematic literature review to make a list of concrete feedback items of interest related to the most emphasised concern of authoring - the effect of the interactive narrative on the user. We identify 47 User Experience (UX) dimensions in the IDN literature that could serve as useful feedback items, covering 8 categories - Agency, Cognition, Immersion, Affect, Drama, Rewards, Motivation and Dissonance. This list combines and untangles how different IDN researchers have interpreted and expressed interest in the complex idea of UX in the past decade and gives us insight into what concrete aspects of UX might be useful to estimate via automated feedback.
\end{abstract}

Keywords: intelligent feedback $\cdot$ co-creation $\cdot$ user experience $\cdot$ interactive narratives $\cdot$ authoring goals $\cdot$ mixed creation

\section{Introduction}

Authoring in Interactive Digital Narratives (IDN) is very challenging. Creators often have to compromise on either the interactive complexity or the quality of the IDN artefact created[31][32]. Most efforts at increasing interactivity, by relying on emergent narratives for example[32], do so at the expense of authorial control and/or quality. Subsequent efforts, like drama managers[33] try to retain complexity and improve quality by introducing new architectures and more sophisticated technology[34]. While some authoring tools support debugging and visualization of the underlying structure [35], as complexity increases these become hard to fully comprehend. A mixed initiative approach has been proposed as a way to overcome this issue of dissociative authoring[29] by giving the author feedback on the potential experiences possible within their work, referred to as Narrative Analytics in [28] and Intelligent Narrative Feedback in [29]. Similarly,

\footnotetext{
* University of Southampton
} 
Artificial Intelligence (AI) and Natural Language Processing (NLP) open up a lot of opportunities for generating intelligent feedback; for example, sentiment networks [39], emotional arcs [52]. By using this feedback to inform authoring, the author could make use of the affordances offered by a complex system while retaining visibility and control, and by extension, quality.

But what exactly is the feedback required by authors? Due to IDN's interdisciplinary and relatively novel nature, collecting these by finding and interviewing a representative set of IDN creators would be challenging. In this paper we have therefore taken an alternative path, and present a systematic review of IDN literature, focusing on the goals and concerns of authors in order to identify an appropriate set of feedback items. Many papers talk about authoring goals, including expressing a specific intent [29], maximizing affordances of IDN[42] and creating a certain effect in the user [30] [42]. However, the most emphasised goal is a good User Experience (UX). Importance of UX is also reflected in how IDN creators often use UX evaluation to measure their success [34].

Therefore, in this paper we focus on identifying the UX dimensions of IDN, with the idea that this could then form the basis of useful automated feedback to authors. The paper is structured as follows: Section 2 discusses related work and background, Section 3 outlines the methodology used for the systematic review, Section 4 presents the results, Section 5 discusses findings and potential applications, and Section 6 outlines future work and conclusions.

\section{Related work}

Previous work has identified some high level categories of useful feedback items for authors. But these deal either with specific problems, for example structural analysis to identify dead ends or short experiences [28], or are not comprehensive in that they focus on specific aspects such as emotional experience [29]. Visualisation is an important element of mixed creation, for example [40] focuses on low level visualization of interaction design as progression maps. Similarly, [38] discusses automatic structural analysis using graph theory, and [37] suggests some low level computational metrics that show correlation with user experience dimensions. We are interested in higher level insights. For example, [41] talks about a similar idea of collecting parameters and then figuring out how to map them to corresponding cognitive processes but limits the scope of their discussion to two feedback items - suspense and surprise.

UX is a very broad area. Audience Studies is a whole field devoted to studying and developing theories surrounding audience's reception of media including IDN [55], and there are conceptualizations of UX (like those presented in [6] and [49]) which describe the process of experience or the relationship between design and experience. However, these do not easily extend to evaluation frameworks or feedback. A number of evaluation frameworks of UX have been proposed for IDN that could form this basis. For example, [43] consolidates Murray's high level interpretation of UX (as Immersion, Agency and Transformation [42]) with Roth's framework[44], to get twelve concrete UX dimensions. Whereas [45] 
uses GEQ[46], NEQ[47], and NTQ[48] to create a specialised UX questionnaire. These are overlapping, but non-identical frameworks. Concepts like affect, curiosity, suspense and identification from [43] are closely related to the emotional engagement dimension in NEQ but are not quite the same. NEQ includes a narrative understanding dimension which is not talked about in [43]. Roth and Koenitz[43] notes how immersion is defined in different ways and settles on its broader high level definition, whereas in work by Kleinman et al.[45] immersion is simply the "capacity of the game contents to be believable".

There is clearly inconsistency and overlap in how UX is defined and understood by different researchers [30]. It is this that motivates our systematic literature review of papers talking about user experience in IDN.

\section{Methodology}

Our systematic literature review follows the established methodology set out in [58], this is formally five steps: outlining the research question, selecting keywords, selecting appropriate electronic resources, constructing a search method, and defining inclusion and exclusion criteria. The research question we are asking in the review is: What concrete aspects of UX are of interest to IDN creators?, and the following section outlines our approach to the other steps.

\subsection{Constructing the Sample}

Springer ${ }^{1}$ was chosen as the electronic resource because it is a database that has good coverage of IDN specific research (for example, ICIDS proceedings). While other resources like CHI Play contain literature on HCI, they tend to be more focused on games. Since we are aiming for IDN focused literature we would have had to filter out a lot of papers. Only papers from the past ten years (2010 2020) were included in order to ensure that the UX dimensions identified were relevant to current approaches and technology. Saturation sampling was chosen as the search method since the potential set of matches was too large to exhaustively analyse. The following search phrase was built by listing commonly used keywords for UX and IDN, searching for the intersection and adjusting to reduce number of irrelevant results :

((user OR player) NEAR/1 (evaluation OR experience OR experiences OR study OR studies OR engagement OR satisfaction OR enjoyment)) AND ("adventure game" OR "adventure games" OR "hypertext fiction" OR "emergent narrative" OR "emergent narratives" OR (interactive NEAR/2 (media OR cinema OR narrative OR narratives OR drama OR dramas OR fiction OR story OR stories OR storytelling) OR (game OR games) NEAR/1 (narrative OR narratives))

Any paper having the above keywords is likely to talk about some aspect of user experience of IDN in some way. However, for practical reasons, we chose

\footnotetext{
${ }^{1}$ Springer Link - https://link.springer.com/
} 
the following inclusion and exclusion criteria to select papers that are likely to give us the most insight into which parameters are of interest:

1. Does the paper focus sufficiently on narrativity and interactivity? There are many types of IDN including Interactive Cinema, Mixed Reality, Storytelling Games and Documentaries and these were all included. Papers were excluded if they were discussing linear narratives, or did not put enough focus on narrativity. The framework proposed in [30] distinguishes narrative goals from system goals. Edutainment and games with a weak narrative component are examples of IDN applications that prioritize system goals over narrative goals. We wish to include only papers that focus primarily on narrative goals. For example, [59] is excluded because while it touches on narrative goals (affect, immersion), the primary focus is on learning.

2. Is the paper about formalizing, measuring or evaluating user experience or some aspect of user experience of IDN or does it include some evaluation of $i t$ ? The kind of papers that are most likely to tell us which aspects of UX are of interest to IDN creators are those that include user experience studies or evaluation frameworks. Such papers also break down user experience into more concrete, measurable parameters. Papers that conduct computational evaluation instead of a user study also give us similar insights. Papers that theoretically formalize UX or discuss it in the context of IDN theory could help concretize UX and make the list more complete.

3. Is the discussion on user experience in the paper detailed and concrete enough to provide relevant insight? Some papers that discuss UX theoretically do so at a very high level [49][50][51] so including them is not useful for our purpose of concretizing it.

\subsection{Coding Process}

To enable saturation sampling, the results of the search were filtered and coded in batches of 20 papers. Each paper in the batch was compared to the criteria, and if it matched was reviewed, and coded as per the following process:

1. UX dimensions were interpreted based on how UX was structured or evaluated in each paper. This was sometimes explicit, for example [43], but sometimes it had to be interpreted from how the authors discussed UX, such as [1] where they evaluate UX in terms of felt and actual understanding, perceived interactivity, narrativity and dissonance.

2. Sometimes, the papers include a hierarchical representation of UX dimensions[43] but since we are interested in concrete concepts only leaf nodes (called low level concepts in this paper) are added to the codebook.

3. If any overlap between the low level concepts is encountered while merging to codebook, the conflicting low level concepts are deconstructed based on their definitions and separated out.

This process is continued until all the papers in the batch are processed. We then repeated the process for the next batch, until we encountered a batch with 
no new codes (saturation point). The number of papers included and new codes added per batch can be seen in Table 1 .

Table 1. Systematic literature review - saturation sampling

\begin{tabular}{|l|l|l|}
\hline Batch number & number of selected papers & number of new codes \\
\hline 0 (seed papers) & 4 & 28 \\
1 & 10 & 13 \\
2 & 6 & 4 \\
3 & 6 & 2 \\
4 & 5 & 0 \\
\hline
\end{tabular}

\subsection{Challenges, nuances and subjective decisions}

We are interested in subjective user experience. Properties completely intrinsic to either system or player are excluded (eg- details pertaining to interaction design like number of choices and extrinsic goals, motivation to start playing, player skills). Some properties, though subjective, are still so intrinsic or specific to either the user or the system that modelling them as intelligent feedback is unlikely to be either feasible or useful - eg Loss of self consciousness, or the desire to save some particular non player character(NPC). In such cases, if an underlying generalizable concept can be discerned based on why the author was interested in this, then it is this concept that is coded. For example loss of self consciousness may have been collected as an indicator of presence. Desire to save an NPC may be interesting because it indicates the degree of attachment or identification with that character. In order to scope and contain growth of the codebook, concepts that are specific to a certain kind of narrative layer (eg - video quality), type of IDN (eg - distance between locations) or multiplayer experiences (eg - social relatedness) and concepts collected for contextualization (eg reasons for quitting, suggestions for improvement) are also excluded.

The structure of UX is specified to different degrees in different papers. For example, it is very clear in [43] but vague in [3]. When the structure of UX is not clear in a paper, its interpretation and consequently the process of identifying the leaf nodes becomes more subjective. This impacts the decision regarding which concepts are concrete enough to be coded as low level. When a concept's concreteness is not clear from a paper, it is decided by considering the context and its description in other papers. This adds a level of subjectivity. Papers sometimes talk about UX concepts that are not central to the scope of the paper - in the background sections, follow up questions, when describing causal relationships to other concepts or in general discussion. Such mentions are often so brief that interpretation of meaning and concreteness would be too subjective, making merging them into the codebook difficult. So concepts that are not central to the framework or evaluation presented in the paper are excluded. This, again, becomes more subjective if the structure is unclear as discussed above. Coding 
A.Revi et al.

for performed by the first author and the results were reviewed and discussed within the research team.

Splitting up old codes and revising the definitions are not seen as adding new concepts. When a code is split, the numbers are revised retrospectively. If enough information is not available to resolve an overlap between two concepts, the more concrete or well defined concept is kept and the other one is discarded. If overlap is minimal, both are kept. Concepts that are very similar are merged into a single low level concept and subtle differences are kept track of in the description.

\section{Results}

This process yielded 47 codes which can be placed under 8 categories as shown in Tables 2 and 3. The third column shows the number of papers in which the code was found. Note that the use of each concept in its original paper might vary slightly from the definitions given below. Sometimes only a subset of the code is mentioned. For example papers with an interest in just excitement or anxiousness, were counted as interested in in game or at game affect type and/or affect intensity accordingly. Papers that don't mention the code but a higher level concept, for example, believability, were counted for all sub-codes based on its interpreted meaning. Papers where a code is mentioned very briefly or not as part of the central work were not counted. The last column shows the references as well as the sense in which concepts were originally used in those papers before they were split up or absorbed either fully or partly into the corresponding code. The following sections describe each category in more detail.

\subsection{Agency}

Six dimensions related to agency were identified: Autonomy or perceived freedom to do as the user wanted is related to the number and quality of options as well as navigational freedom. Effectance or perceived meaningfulness and impact of choices is related to being able to recognize when and how the storyworld was causally affected by the player's actions through clear feedback. This is a requirement for control which means being able to intentionally bring about specific goals and outcomes. [5] is interested in the idea of persuasion or degree to which the player was persuaded to take a particular action. Conversely, [34] talks about the degree to which the player felt like he was being manipulated by the system. These concepts were coded as manipulation. [6] talks about personalisation or the extent to which the user feels that they experienced a story unique to their actions. This is related to the extent to which a user feels like they expressed their intention and extent to which they feel like the system understood this expression and has responded to it accordingly. Additionally usability, which refers to the user's experience with both the hardware and the software from a HCI perspective is also put under this category. 
Table 2. Codebook: UX dimensions

\begin{tabular}{|c|c|c|c|}
\hline Category & Code & num & references \\
\hline \multirow{6}{*}{ Agency } & Autonomy & 6 & $\begin{array}{l}\text { navigational freedom[12][13], availability of desired } \\
\text { choices[17][27] autonomy[43][34] }\end{array}$ \\
\hline & Effectance & 7 & $\begin{array}{l}\text { effectance[11][15][43][21] unnecessary choices }[17] \\
\text { meaningful interaction [30], actions had no effect }[27]\end{array}$ \\
\hline & Control & 4 & flow $[10][15]$ control[17][3] \\
\hline & Manipulation & 3 & $\begin{array}{l}\text { likelihood of successful manipulation[5] } \\
\text { autonomy[43]non limitation[34] }\end{array}$ \\
\hline & Personalization & 1 & personalization $[6]$ \\
\hline & Usability & 7 & $\begin{array}{l}\text { usability[11][19][17][26][43][3] effort to change } \\
\text { story[19] }\end{array}$ \\
\hline \multirow{8}{*}{ Cognition } & $\begin{array}{l}\text { Narrative } \\
\text { Understanding }\end{array}$ & 9 & $\begin{array}{l}\text { Epiphany }[9], \text { observed understanding }[7] \\
\text { understanding theme, intent }[12][13][14][1] \text { narrative } \\
\text { understanding }[16][45] \text { intelligibility }[30]\end{array}$ \\
\hline & $\begin{array}{l}\text { Game } \\
\text { Understanding }\end{array}$ & 9 & $\begin{array}{l}\text { flow }[10][6] \text { clear feedback,goals }[15] \\
\text { expectations }[11][26][14] \text { understanding how to } \\
\text { interact }[19][8] \text { system intelligibility }[30]\end{array}$ \\
\hline & $\begin{array}{l}\text { Perceived } \\
\text { Understanding }\end{array}$ & 4 & epiphany $[9]$ closure[30]perceived understanding $[7][1]$ \\
\hline & $\begin{array}{l}\text { Logical } \\
\text { Consistency }\end{array}$ & 11 & $\begin{array}{l}\text { epiphany }[9] \text { believability }[7][26][43][11][14][3] \text { visual } \\
\text { communication[16] surprise, incongruency[41] } \\
\text { immersion[45]coherence[34] inconsistencies[34][3] }\end{array}$ \\
\hline & \begin{tabular}{|l|} 
Ambiguity \\
\end{tabular} & 1 & level of abstractness[30] \\
\hline & $\begin{array}{l}\text { Perceived } \\
\text { Realism }\end{array}$ & 10 & $\begin{array}{l}\text { believability[7][26][43] character } \\
\text { believability[11][14][3] intelligent response }[15] \\
\text { perceived realism[16]presence, immersion, } \\
\text { naturality[45] breaks - sense of strangeness[34] }\end{array}$ \\
\hline & Challenge & 5 & difficulty[10][15][6] was demanding[17] flow[43][10] \\
\hline & Storification & 4 & $\begin{array}{l}\text { variation in experienced story[12] degree of } \\
\text { storification[27] emergent narrative[24] narrative } \\
\text { understanding, mental models[45] }\end{array}$ \\
\hline \multirow{8}{*}{ Immersion } & Presence & 7 & $\begin{array}{l}\text { sensory, imaginative immersion[10] } \\
\text { presence[11][43][16][45] Loss of Self } \\
\text { Consciousness[15] emotional, spacial immersion[21] }\end{array}$ \\
\hline & $\begin{array}{l}\text { Suspension of } \\
\text { disbelief }\end{array}$ & 4 & believability[7][26][43] role identification[14] \\
\hline & Degree of focus & 10 & $\begin{array}{l}\text { Absorption, attention, focus }[8][16][17][45][15] \\
\text { flow[10][11][45][6], transformation of time[15], } \\
\text { attraction[18], awareness of surroundings[19] }\end{array}$ \\
\hline & Object of focus & 3 & attraction towards[18][8] reference[20] \\
\hline & Identification & 9 & $\begin{array}{l}\text { role adoption[11][26] cognitive/behavioral } \\
\text { responses[15] emotional engagement[16] suspense[43] } \\
\text { identification[43][34][16][14] perspective[20] } \\
\text { like/dislike[4] }\end{array}$ \\
\hline & Continuity & 7 & $\begin{array}{l}\text { flow }[10][11][22][6], \text { inconsistencies }[34][3], \text { breaks }[34], \\
\text { relatedness }[4]\end{array}$ \\
\hline & Aesthetics & 4 & sensory immersion[10] pleasantness[11][26][17] \\
\hline & Safety & 1 & safety $[6]$ \\
\hline
\end{tabular}


Table 3. Codebook: UX Dimensions contd

\begin{tabular}{|c|c|c|c|}
\hline Category & Code & num & references \\
\hline \multirow[t]{4}{*}{ Affect } & $\begin{array}{l}\text { in game affect } \\
\text { intensity }\end{array}$ & 17 & $\begin{array}{l}\text { Suspense, tension, anxiety }[7][10][12][21][25][26][43], \\
\text { Affect, emotional state }[7][10][11][15][26][43], \\
\text { Enjoyment[7][11][22], Flow[10][45], emotional } \\
\text { engagement/immersion[13][45][16][21], behavioural } \\
\text { responses[15], Reception[16], closure[6], } \\
\text { Curiosity[43], Pleasure[34], Surprise[3][43] }\end{array}$ \\
\hline & $\begin{array}{l}\text { in game affect } \\
\text { type }\end{array}$ & 15 & $\begin{array}{l}\text { suspense[7][10][12][25][43] affect[7][10][11][15][24][43] } \\
\text { enjoyment[7][11] flow[10][45][43] reception }[16] \\
\text { closure[6] emotional state[18][26] curiosity }[43] \\
\text { emotional engagement[45] pleasure[34] surprise[3] }\end{array}$ \\
\hline & $\begin{array}{l}\text { at game affect } \\
\text { intensity }\end{array}$ & 5 & $\begin{array}{l}\text { annoyance[17], enjoyment [26][34][43] interest,fun[45] } \\
\text { flow }[45][43]\end{array}$ \\
\hline & $\begin{array}{l}\text { at game affect } \\
\text { type } \\
\end{array}$ & 6 & $\begin{array}{l}\text { annoyance[17]affect-technical[24] } \\
\text { enjoyment[26][34][43] flow[45][43] interest, fun[45] }\end{array}$ \\
\hline \multirow{8}{*}{ Drama } & Curiosity & 10 & $\begin{array}{l}\text { curiosity }[11][7][13][14][17][22][26][43][3] \text { temporal } \\
\text { immersion }[21]\end{array}$ \\
\hline & Closure & 2 & narrative closure $[30][6]$ \\
\hline & Uncertainty & 13 & $\begin{array}{l}\text { Epiphany [9], Suspense }[7][10][11][12][41][26][43], \\
\text { imaginative/emotional immersion[10][21] } \\
\text { curiosity[26][43] believability[11] } \\
\text { predictability[17][41][3] Surprise[41][3] }\end{array}$ \\
\hline & Expectation & 9 & $\begin{array}{l}\text { Suspense }[7][26][11][12][41] \text { imaginative/ emotional } \\
\text { immersion }[10][21] \text { expectation[14][41] surprise[3][41] }\end{array}$ \\
\hline & \begin{tabular}{|l|l|} 
Desired \\
outcomes
\end{tabular} & 3 & $\begin{array}{l}\text { satisfaction with ending[17] dreaded/desirable } \\
\text { outcomes [43][17] }\end{array}$ \\
\hline & Novelty & 1 & novelty $[17]$ \\
\hline & Variety & 2 & variation in experienced story[12] variety[34] \\
\hline & Themes & 4 & theme[13][12]images[34] escalating climax[3] \\
\hline \multirow{4}{*}{ Rewards } & $\begin{array}{l}\text { Eudaimonic } \\
\text { appreciation }\end{array}$ & 4 & $\begin{array}{l}\text { eudaimonic appreciation }[7][43] \text { meaningfulness, } \\
\text { take-away[14] pleasures of reflection }[6]\end{array}$ \\
\hline & $\begin{array}{l}\text { Sense of } \\
\text { reward }\end{array}$ & 5 & $\begin{array}{l}\text { Auteletic Experience, intrinsic rewards[15] feeling } \\
\text { rewarded[6][17][3] curiosity[43] }\end{array}$ \\
\hline & Learning & 1 & cognitive responses[15] \\
\hline & Interest & 2 & increase of interest in the topic[14] edurability[17] \\
\hline \multirow{6}{*}{ Motivation } & to continue & 5 & continuation desire[2][24][1][45] engagement [22] \\
\hline & to replay & 5 & desire to replay[10][12][23][24][17] \\
\hline & to interact & 2 & $\begin{array}{l}\text { desire to explore/get involved[13] motivation to } \\
\text { change story[19] }\end{array}$ \\
\hline & Objectives & 1 & objectives[24] \\
\hline & Activities & 1 & activities[24] \\
\hline & Reinforcement & 2 & catharsis [6]accomplishments[24] \\
\hline \multirow{3}{*}{ Dissonance } & Interactivity & 3 & $\begin{array}{l}\text { frequency choices[17]participation [21] } \\
\text { interactivity[1] }\end{array}$ \\
\hline & Narrativity & 1 & perceived narrativity[1] \\
\hline & Dissonance & 4 & $\begin{array}{l}\text { disruption[17][21] narrative play[23] separation of } \\
\text { interactivity and narrativity[1] }\end{array}$ \\
\hline
\end{tabular}




\subsection{Cognition}

Eight dimensions related to cognition were identified. Logical consistency is consistency of events and character behaviour as well as the themes and messages of the narrative. Ambiguity is the level of abstraction or clarity of the content. According to [30], narrative is said to be unambiguous when the content predisposes audience towards one and only one interpretation. Degree of storification is the extent to which a self-narrated story and mental models are created internally in the player. Narrative understanding is a measure of how much the user understands the story as intended by the author. Game understanding refers to how much the user understands game elements like clarity of goals, rules, boundaries and how to interact with and influence story. Perceived understanding is the degree to which users felt like they understood the narrative rather than their interpretation of it being conjecture. Challenge is a measure of how difficult users found the game and if they found that level of difficulty necessary, meaningful and enjoyable. Perceived realism is the game's closeness or resonance with reality judged on plausibility of events and character behaviour, perceived intelligence of system and characters and the degree to which the experience does not feel engineered.

\subsection{Immersion}

Eight dimensions of Immersion were identified. Presence is related to the degree to which the user feels like they have left the actual world and entered the story, the feeling of being in the mediated space with mediated people. Suspension of disbelief refers to the degree to which the player loses awareness of the medium through which the experience is transmitted. Degree of focus or absorption refers to the degree to which the user's abilities and attention is

focused on the experience. Sometimes there is also interest in the Object of Focus - game, narrative or reality frame. Identification or connection refers to the perspective adopted by the user as well as affective disposition towards different story elements. It includes the degree to which users identify with the role and the story as well as the degree of attachment, empathy, and sympathy felt towards different characters. Continuity is the degree and duration of ongoing continuous involvement in the storyworld, merging action and awareness and the absence of breaks in the narrative caused by sudden changes in tone or the occurrence of abrupt, unconnected events. Aesthetic pleasantness, or the degree to which the user finds the setting and layout appealing, is also included in this category. Though not commonly discussed, [6] also talks about immersion in relation to the user's perceived Safety and how past a certain level of immersion, the user is at the risk of feeling unsafe.

\subsection{Affect}

While affect encompasses a vast range of experiences, we listed it in the codebook as in game and at game affect type and intensity. Affect intensity is the 
intensity of emotional arousal and engagement felt. Affect type refers to the type of affect. More than 40 types of affects were listed from all papers together (e.g. Exhilaration, Anger, Frustration, etc.). Listing them out as separate codes does not seem useful but an important distinction to make is between affect felt towards the application or the game itself versus the same emotions aroused by events in the narrative. This is similar to the idea of at-game and in-game frustration described in [53]. This is differentiated as at-game or in-game affect.

\subsection{Drama}

This category relates to traditional narratology and drama. Curiosity is defined here as the degree of interest in the story, progression and actionable possibilities, or simply, a desire to find out more. Themes refers to topics, images and tropes that the user identified in the experience. Novelty refers to perceived newness and innovation in different elements of the experience. Variety refers to number and diversity of choices, experiences and actions. Closure is the degree to which users felt like the experienced story was complete and that the relevance of all story elements was revealed [30]. Suspense and surprise were absorbed into other concepts including uncertainty or predictability of progression and system responses and expectation aroused by a situation or narrative prompt. Suspense also includes the code - desired outcomes which refers to the user's dreaded and desirable consequences as well as satisfaction with how the story progressed.

\subsection{Rewards}

Four dimension related to rewards were identified. Eudaimonic appreciation is a measure of perceived cognitive and emotional meaningfulness of the experience (in terms of deducing general life lessons, insights into the meaning of life or how much the source challenges perceptions and life stories of the user.)Sense of accomplishment is related to the degree to which the player found the experience intrinsically rewarding and considers his investment in it worthwhile. Learning is a measure of how much playing game improved skill,knowledge or intelligence and arousal of interest stands for the degree to which the experience created an interest in the topic or in IDN.

\subsection{Motivation}

Six dimensions related to motivation were identified - Objectives refers to intrinsic objectives that the user developed while playing. Activities refers to what types of actions (interface/solve/ sense/ socialize/experience story and characters/ explore/experiment/create/destroy) users planned to or wanted to perform. Reinforcement refers to types of rewards that kept them motivated (completion, advancement or achievement). This was included in this category rather than Rewards because they were interested in the reward in the context of continuation desire. The remaining dimensions - intensity of desire to continue playing, desire to interact and desire to replay are self explanatory. 


\subsection{Dissonance}

The final category has only three codes. Interactivity refers to the user's perception and satisfaction of the degree of participation or interactivity. Narrativity refers to user's perception of the game's focus on narrative elements as compared to its game elements. Dissonance stands for the degree of perceived dissonance or harmony experienced between game and narrative elements.

\section{Discussion}

The main contribution of this paper is the codebook shown in tables 2 and 3 . While there have been many efforts to formalize and break down UX into simpler dimensions, they have resulted in many different interpretations - each concept being defined slightly differently in different papers and concepts overlapping each other to varying degrees in their many definitions. Our intention is not to promote what we believe UX should look like, or to claim that this is a definitive list of UX dimensions, rather the work presented here brings together and untangles those interpretations of UX expressed in the IDN literature, showing us ultimately what concrete dimensions of UX can be considered to be of interest to this specific community. The counts associated with each concept also gives us some insight into the relative interest and usefulness of modelling different dimensions of UX, although there will be other factors at play (for example, how commonly they are discussed in other communities, or the availability of instruments with which to measure them). The references column also tells us in what sense the interest was originally expressed.

Researchers are often interested only in specific aspects of UX but this table may be used in evaluation to give a broader and more complete understanding of UX for IDN, and to identify dimensions that are considered less frequently. For example, while effectance, autonomy and usability are widely evaluated, concepts like control, manipulation and personalization are given less attention, even though they might provide useful insights about the user's experience of agency. Other commonly used evaluation frameworks like [43] and [46] can be seen as focusing on a subset of the codes listed.

The main motivation for our list is so it can be used as a starting point for generating automated feedback for the author to assist authoring. For example, in game affect type and intensity are concepts that seem to be of interest to most IDN creators and there seems to be a good amount of literature on affect detection using NLP techniques(eg- [52][54]). The work presented in this paper can act as a starting point for such an investigation. Mapping these UX dimensions against a literature review of NLP techniques will give us insight into such possibilities. In the case of some of these concepts, like perceived realism and logical consistency, it is more straightforward to see what properties of the source cause the desired effects in the user. On the other hand, concepts like presence and degree of focus have complex causal relationships with system and content properties as well the other concepts and would be more difficult to model. Work in media psychology and audience studies like [55], [56] and [57] discusses some 
of these concepts and the nature of their relationships with each other and the source more closely.

Authors usually want to create a certain pattern of effects on the user. For example, [43] talks about cyclical building up and relieving of curiosity. While it might be possible for the author to visualize, predict and create this effect when writing linear stories, it becomes hard to keep track of this when the space of potential stories grows. However, if curiosity, expectation, uncertainty and affective responses can be automatically modelled, then it should be possible to reflect this to the author for all the possible paths through their narrative, allowing them to more efficiently tailor the content and tune its effects on the user along all branches, resulting in better authorial control and user experience.

\section{Conclusion}

In this paper, we have examined what the IDN community considers to be the important UX dimensions for its users, readers and players. Our goal is to understand what automated feedback might be useful to IDN authors. To gather feedback items that will help the author we performed a systematic review of UX in the IDN literature. This process untangles the many overlapping interpretations of UX by different IDN researchers and yields a list of 47 feedback items covering 8 categories: Agency, Cognition, Immersion, Affect, Drama, Rewards, Motivation, and Dissonance. Our future work will investigate AI and NLP techniques that will help automatically estimate these. Integrating such feedback to an authoring environment would not only help detect problems but would also allow authors to closely tailor the experience for their users without massivescale iterative playtesting. It could free them to write more complex narratives without losing sight of how each branch of those narratives impacts the user.

Authoring goals go beyond UX, and these could also be assisted by automation. For example, the desire to express a specific authorial intent calls for feedback at a lower level than UX. This is in part accomplished by visualizations such as those in Novella[35] and progression maps[40], but as complexity grows, more insightful views like sentiment networks, maps, timelines and dramatic arcs are also worth considering. Reviewing commonly applied narrative devices, formalisms, conventions and authoring practices might tell us which would be most useful. Similarly reviewing critical analyses of IDN works and IDN theory might show us what feedback items can help the author maximise the use of IDN affordances or train them in the art of IDN [36]. This might also mean feedback that helps them fluently use the authoring tool (e.g. system feedback [29]).

We hope that this research can become a foundation stone for these future mixed-initiative approaches. By focusing on the dimensions of UX specifically of interest to the IDN community we have shown the range of feedback that automation might usefully provide, as well as framing the existing work on UX as an evaluation method. Ultimately, providing IDN authors with automated feedback items should not only allow individual authors more control, but by enabling new complexity, it should also help IDN to mature as an art form. 


\section{References}

1. Bevensee, S. H., Dahlsgaard Boisen, K. A., Olsen, M. P., Schoenau-Fog, H., \& Bruni, L. E. (2012). Project Aporia - An Exploration of Narrative Understanding of Environmental Storytelling in an Open World Scenario (pp. 96-101). https://doi.org/10.1007/978-3-642-34851-8_9

2. Bevensee, S. H., Dahlsgaard Boisen, K. A., Olsen, M. P., Schoenau-Fog, H., \& Bruni, L. E. (2012). Aporia - Exploring Continuation Desire in a Game Focused on Environmental Storytelling (pp. 42-47). https://doi.org/10.1007/978-3-642-348518 8 4

3. Seif El-Nasr, M., Milam, D., \& Maygoli, T. (2013). Experiencing interactive narrative: A qualitative analysis of Façade. Entertainment Computing, 4(1), 39-52. https://doi.org/10.1016/j.entcom.2012.09.004

4. Vriesede, T., \& Nack, F. (2011). StoryStream: Unrestricted mobile exploration of city neighbourhoods enriched by the oral presentation of user-generated stories. Lecture Notes in Computer Science (Including Subseries Lecture Notes in Artificial Intelligence and Lecture Notes in Bioinformatics), 7069 LNCS, 231-242. https://doi.org/10.1007/978-3-642-25289-1_25

5. Figueiredo, R., \& Paiva, A. (2011). "I'm sure I made the right choice!" - Towards an architecture to influence player's behaviors in interactive stories. Lecture Notes in Computer Science (Including Subseries Lecture Notes in Artificial Intelligence and Lecture Notes in Bioinformatics), 7069 LNCS, 152-157. https://doi.org/10.1007/978-3-642-25289-1_16

6. Patrickson, B. (2011). Multi-user interactive drama: A micro user drama in process. Lecture Notes in Computer Science (Including Subseries Lecture Notes in Artificial Intelligence and Lecture Notes in Bioinformatics), 7069 LNCS, 199-206. https://doi.org/10.1007/978-3-642-25289-1_22

7. van Enschot, R., Boogaard, I., Koenitz, H., \& Roth, C. (2019). The potential of interactive digital narratives. agency and multiple perspectives in last hijack interactive. Lecture Notes in Computer Science (Including Subseries Lecture Notes in Artificial Intelligence and Lecture Notes in Bioinformatics), 11869 LNCS, 158-169. https://doi.org/10.1007/978-3-030-33894-7_17

8. Socas-Guerra, V., \& González-González, C. S. (2012). User attention in nonlinear narratives: A case of study. Lecture Notes in Computer Science (Including Subseries Lecture Notes in Artificial Intelligence and Lecture Notes in Bioinformatics), 7545 LNCS, 104-111. https://doi.org/10.1007/978-3-642-33760-4_9

9. Di Pastena, A., Jansen, D., de Lint, B., \& Moss, A. (2018). "The link out": Towards a theory of epiphany in digital games. Lecture Notes in Computer Science (Including Subseries Lecture Notes in Artificial Intelligence and Lecture Notes in Bioinformatics), 11318 LNCS, 206-216. https://doi.org/10.1007/978-3-030-04028-4_21

10. Vayanou, M., Ioannidis, Y., Loumos, G., \& Kargas, A. (2019). How to play storytelling games with masterpieces: from art galleries to hybrid board games. Journal of Computers in Education, 6(1), 79-116. https://doi.org/10.1007/s40692-018-0124-y

11. Roth, C., Klimmt, C., Vermeulen, I. E., \& Vorderer, P. (2011). The experience of interactive storytelling: Comparing "Fahrenheit" with "Façade." Lecture Notes in Computer Science (Including Subseries Lecture Notes in Artificial Intelligence and Lecture Notes in Bioinformatics), 6972 LNCS, 13-21. https://doi.org/10.1007/9783-642-24500-8_2

12. Schoenau-Fog, H., Bruni, L. E., Khalil, F. F., \& Faizi, J. (2013). Authoring for engagement in plot-based interactive dramatic experiences for learning. Lecture Notes 
in Computer Science (Including Subseries Lecture Notes in Artificial Intelligence and Lecture Notes in Bioinformatics), 7775 LNCS, 1-19. https://doi.org/10.1007/9783-642-37919-2_1

13. Schoenau-Fog, H., Bruni, L. E., Khalil, F. F., \& Faizi, J. (2010). First person victim: Developing a 3D interactive dramatic experience. Lecture Notes in Computer Science (Including Subseries Lecture Notes in Artificial Intelligence and Lecture Notes in Bioinformatics), 6432 LNCS, 240-243. https://doi.org/10.1007/978-3-64216638-9_32

14. Roth, C. (2019). The 'Angstfabriek' Experience: Factoring Fear into Transformative Interactive Narrative Design. Lecture Notes in Computer Science (Including Subseries Lecture Notes in Artificial Intelligence and Lecture Notes in Bioinformatics), 11869 LNCS, 101-114. https://doi.org/10.1007/978-3-030-33894-7_11

15. Moser, C., \& Fang, X. (2014). Narrative control and player experience in role playing games: Decision points and branching narrative feedback. Lecture Notes in Computer Science (Including Subseries Lecture Notes in Artificial Intelligence and Lecture Notes in Bioinformatics), 8512 LNCS(PART 3), 622-633. https://doi.org/10.1007/978-3-319-07227-2_59

16. Zagalo, N., Louchart, S., \& Soto-Sanfiel, M. T. (2010). Users and evaluation of interactive storytelling. Lecture Notes in Computer Science (Including Subseries Lecture Notes in Artificial Intelligence and Lecture Notes in Bioinformatics), 6432 LNCS, 287-288. https://doi.org/10.1007/978-3-642-16638-9_44

17. Kolhoff, L., \& Nack, F. (2019). How relevant is your choice? : User engagement and perceived agency in interactive digital narratives on video streaming platforms. Lecture Notes in Computer Science (Including Subseries Lecture Notes in Artificial Intelligence and Lecture Notes in Bioinformatics), 11869 LNCS, 73-85. https://doi.org/10.1007/978-3-030-33894-7_9

18. Grinder-Hansen, A., \& Schoenau-Fog, H. (2013). The elements of a narrative environment exploring user reactions in relation to game elements. Lecture Notes in Computer Science (Including Subseries Lecture Notes in Artificial Intelligence and Lecture Notes in Bioinformatics), 8230 LNCS, 186-191. https://doi.org/10.1007/978-3-319-02756-2_23

19. De Lima, E. S., Feijo, B., Barbosa, S., Furtado, A. L., Ciarlini, A., \& Pozzer, C. (2011). Draw your own story: Paper and pencil interactive storytelling. Lecture Notes in Computer Science (Including Subseries Lecture Notes in Artificial Intelligence and Lecture Notes in Bioinformatics), 6972 LNCS, 1-12. https://doi.org/10.1007/978-3-642-24500-8_1

20. Theune, M., Linssen, J., \& Alofs, T. (2013). Acting, playing,or talking about the story: An annotation scheme for communication during interactive digital storytelling. Lecture Notes in Computer Science (Including Subseries Lecture Notes in Artificial Intelligence and Lecture Notes in Bioinformatics), 8230 LNCS, 132-143. https://doi.org/10.1007/978-3-319-02756-2_17

21. Vosmeer, M., \& Schouten, B. (2014). Interactive cinema: Engagement and interaction. Lecture Notes in Computer Science (Including Subseries Lecture Notes in Artificial Intelligence and Lecture Notes in Bioinformatics), 8832, 140-147. https://doi.org/10.1007/978-3-319-12337-0_14

22. Soares De Lima, E., Feijó, B., \& Furtado, A. L. (n.d.). Video-based interactive storytelling using real-time video compositing techniques. https://doi.org/10.1007/s11042-017-4423-5

23. Mitchell, A., \& McGee, K. (2011). Supporting rereadability through narrative play. Lecture Notes in Computer Science (Including Subseries Lecture Notes in 
Artificial Intelligence and Lecture Notes in Bioinformatics), 7069 LNCS, 67-78. https://doi.org/10.1007/978-3-642-25289-1_8

24. Schoenau-Fog, H. (2011). Hooked! - Evaluating engagement as continuation desire in interactive narratives. Lecture Notes in Computer Science (Including Subseries Lecture Notes in Artificial Intelligence and Lecture Notes in Bioinformatics), 7069 LNCS, 219-230. https://doi.org/10.1007/978-3-642-25289-1_24

25. Bida, M., Cěrný, M., \& Brom, C. (2013). Towards automatic story clustering for interactive narrative authoring. Lecture Notes in Computer Science (Including Subseries Lecture Notes in Artificial Intelligence and Lecture Notes in Bioinformatics), 8230 LNCS, 95-106. https://doi.org/10.1007/978-3-319-02756-2_11

26. Szilas, N., \& Ilea, I. (2014). Objective metrics for interactive narrative. Lecture Notes in Computer Science (Including Subseries Lecture Notes in Artificial Intelligence and Lecture Notes in Bioinformatics), 8832, 91-102. https://doi.org/10.1007/978-3-319-12337-0_9

27. Hannesson, H. J., Reimann-Anderse, T., Burelli, P., \& Bruni, L. E. (2015). Connecting the dots: Quantifying the narrative experience in interactive media. Lecture Notes in Computer Science (Including Subseries Lecture Notes in Artificial Intelligence and Lecture Notes in Bioinformatics), 9445, 189-201. https://doi.org/10.1007/978-3-319-27036-4_18

28. Millard, D. E., West-taylor, C., Howard, Y., \& Packer, H. (2018). The Ideal ReaderBot : Machine Readers and Narrative Analytics.

29. Suttie, N., Louchart, S., Aylett, R., \& Lim, T. (2013). Theoretical considerations towards authoring emergent narrative. Lecture Notes in Computer Science (Including Subseries Lecture Notes in Artificial Intelligence and Lecture Notes in Bioinformatics), 8230 LNCS, 205-216. https://doi.org/10.1007/978-3-319-02756-2_25

30. Bruni, L. E., \& Baceviciute, S. (2013). Narrative intelligibility and closure in interactive systems. Lecture Notes in Computer Science (Including Subseries Lecture Notes in Artificial Intelligence and Lecture Notes in Bioinformatics), 8230 LNCS, 13-24. https://doi.org/10.1007/978-3-319-02756-2_2

31. Bruckman, A. (1990). The Ccombinatorics of Storytelling: Mystery Train Interactive.

32. Aylett, R. (n.d.). Emergent Narrative, Social Immersion and "Storification."

33. Roberts, D. L., \& Isbell, C. L. (n.d.). Desiderata for Managers of Interactive Experiences: A Survey of Recent Advances in Drama Management.

34. R. Utsch, M. N., Pappa, G. L., Chaimowicz, L., \& Prates, R. O. (2020). A New NonDeterministic Drama Manager for Adaptive Interactive Storytelling. Entertainment Computing, 100364. https://doi.org/10.1016/j.entcom.2020.100364

35. Green, D. (2018). Novella: An authoring tool for interactive storytelling in games. Lecture Notes in Computer Science (Including Subseries Lecture Notes in Artificial Intelligence and Lecture Notes in Bioinformatics), 11318 LNCS, 556-559. https://doi.org/10.1007/978-3-030-04028-4_66

36. Koenitz, H., Dubbelman, T., \& Roth, C. (2019). An educational program in interactive narrative design. Lecture Notes in Computer Science (Including Subseries Lecture Notes in Artificial Intelligence and Lecture Notes in Bioinformatics), 11869 LNCS, 22-25. https://doi.org/10.1007/978-3-030-33894-7_3

37. Szilas, N., \& Ilea, I. (2014). Objective metrics for interactive narrative. Lecture Notes in Computer Science (Including Subseries Lecture Notes in Artificial Intelligence and Lecture Notes in Bioinformatics), 8832, 91-102. https://doi.org/10.1007/978-3-319-12337-0_9 
38. Partlan, N., Carstensdottir, E., Snodgrass, S., Kleinman, E., Smith, G., Harteveld, C., \& Seif El-Nasr, M. (2018). Exploratory Automated Analysis of Structural Features of Interactive Narrative. In Fourteenth Artificial Intelligence and Interactive Digital Entertainment Conference. www.aaai.org

39. Labatut, V., \& Bost, X. (2019). Extraction and analysis of fictional character networks: A survey. ACM Computing Surveys, 52(5), 1-40. https://doi.org/10.1145/3344548

40. Carstensdottir, E., Partlan, N., Sutherland, S., Duke, T., Ferris, E., Richter, R. M., Valladares, M., \& Seif El-Nasr, M. (n.d.). Progression Maps: Conceptualizing Narrative Structure for Interaction Design Support. https://doi.org/10.1145/3313831.3376527

41. Bruni, L. E., Baceviciute, S., \& Arief, M. (2014). Narrative cognition in interactive systems: Suspense-surprise and the P300 ERP component. Lecture Notes in Computer Science (Including Subseries Lecture Notes in Artificial Intelligence and Lecture Notes in Bioinformatics), 8832, 164-175. https://doi.org/10.1007/9783-319-12337-0_17

42. Murray, J. (1997). Hamlet on the holodeck: The future of narrative in cyberspace (2001 ed.).

43. Roth, C., \& Koenitz, H. (2016). Evaluating the user experience of interactive digital narrative. AltMM 2016 - Proceedings of the 1st International Workshop on Multimedia Alternate Realities, Co-Located with ACM Multimedia 2016, 31-36. https://doi.org/10.1145/2983298.2983302

44. Vermeulen, I. E., Roth, C., Vorderer, P., \& Klimmt, C. (2010). Measuring user responses to interactive stories: Towards a standardized assessment tool. Lecture Notes in Computer Science (Including Subseries Lecture Notes in Artificial Intelligence and Lecture Notes in Bioinformatics), 6432 LNCS, 38-43. https://doi.org/10.1007/9783-642-16638-9_7

45. Kleinman, E., Caro, K., \& Zhu, J. (2020). From immersion to metagaming: Understanding rewind mechanics in interactive storytelling. Entertainment Computing, 33, 100322. https://doi.org/10.1016/j.entcom.2019.100322

46. Brockmyer, J. H., Fox, C. M., Curtiss, K. A., McBroom, E., Burkhart, K. M., \& Pidruzny, J. N. (2009). The development of the Game Engagement Questionnaire: A measure of engagement in video game-playing. Journal of Experimental Social Psychology, 45(4), 624-634. https://doi.org/10.1016/j.jesp.2009.02.016

47. Busselle, R., \& Bilandzic, H. (2009). Measuring Narrative Engagement. Media Psychology, 12(4), 321-347. https://doi.org/10.1080/15213260903287259

48. Green, M. C., \& Brock, T. C. (2000). The Role of Transportation in the Persuasiveness of Public Narratives. 79(5), 701-721. https://doi.org/10.1037/00223514.79.5.701

49. Suovuo, T. "bgt," Skult, N., Joelsson, T. N., Skult, P., Ravyse, W., \& Smed, J. (2020). The Game Experience Model (GEM) (pp. 183-205). https://doi.org/10.1007/978-3-030-37643-7_8

50. Patrickson, B. (2011). Multi-user interactive drama: The macro view - Three structural layers. Lecture Notes in Computer Science (Including Subseries Lecture Notes in Artificial Intelligence and Lecture Notes in Bioinformatics), 7069 LNCS, 317-321. https://doi.org/10.1007/978-3-642-25289-1_38

51. Cavazza, M., \& Young, R. M. (2017). Introduction to Interactive Storytelling. In Handbook of Digital Games and Entertainment Technologies (pp. 377-392). Springer Singapore. https://doi.org/10.1007/978-981-4560-50-4_55 
52. Reagan, A. J., Mitchell, L., Kiley, D., Danforth, C. M., \& Dodds, P. S. (2016). The emotional arcs of stories are dominated by six basic shapes. EPJ Data Science, 5(1). https://doi.org/10.1140/epjds/s13688-016-0093-1

53. Miller, M. K., \& Mandryk, R. L. (2016). Differentiating inGame Frustration from at-Game Frustration using Touch Pressure. https://doi.org/10.1145/2992154.2992185

54. Alm, C. O., Roth, D., \& Sproat, R. (2005). Emotions from text. Proceedings of the Conference on Human Language Technology and Empirical Methods in Natural Language Processing - HLT '05, 579-586. https://doi.org/10.3115/1220575.1220648

55. Green, M. C., \& Jenkins, K. M. (2014). Interactive Narratives: Processes and Outcomes in User-Directed Stories. Journal of Communication, 64(3), 479-500. https://doi.org/10.1111/jcom.12093

56. Christy, K. R., \& Fox, J. (2016). Transportability and Presence as Predictors of Avatar Identification Within Narrative Video Games. Cyberpsychology, Behavior, and Social Networking, 19(4), 283-287. https://doi.org/10.1089/cyber.2015.0474

57. Witmer, B. G., \& Singer, M. J. (1998). Measuring presence in virtual environments: A presence questionnaire. Presence: Teleoperators and Virtual Environments, 7(3), 225-240. https://doi.org/10.1162/105474698565686

58. Kitchenham, B. (2004). Procedures for Performing Systematic Reviews.

59. Novak, E. (2015). A critical review of digital storyline-enhanced learning. Educational Technology Research and Development, 63(3), 431-453. https://doi.org/10.1007/s11423-015-9372-y 